\title{
A study of pediatric cerebral arteriovenous malformations: clinical presentation, radiological features, and long-term functional and educational outcomes with predictors of sustained neurological deficits
}

\author{
Vijay M. Ravindra, MD, MSPH, ${ }^{1}$ Robert J. Bollo, MD, ${ }^{1}$ Ilyas M. Eli, MD, ${ }^{1}$ Julius Griauzde, MD, ${ }^{2}$ \\ Arianna Lanpher, BA, ${ }^{3}$ Jennifer Klein, APRN, ${ }^{3}$ Huirong Zhu, PhD, ${ }^{4}$ Douglas L. Brockmeyer, MD, ${ }^{1}$ \\ John R. W. Kestle, MD, ${ }^{1}$ William T. Couldwell, MD, PhD, ${ }^{1}$ R. Michael Scott, MD, ${ }^{3}$ and \\ Edward Smith, MD ${ }^{3}$ \\ 'Division of Pediatric Neurosurgery, Primary Children's Hospital, University of Utah, Salt Lake City, Utah; '2Department of \\ Radiology, University of Michigan, Ann Arbor, Michigan; ${ }^{3}$ Department of Neurosurgery, Harvard Medical School, Division of \\ Pediatric Neurosurgery, Boston Children's Hospital, Boston, Massachusetts; and ${ }^{2}$ Department of Surgery, Texas Children's \\ Hospital, Houston, Texas
}

OBJECTIVE Large experiences with the treatment of pediatric arteriovenous malformations (AVMs) remain relatively rare, with limited data on presentation, treatment, and long-term functional outcomes. Because of the expected long lifespan of children, caregivers are especially interested in outcome measures that assess quality of life. The authors' intention was to describe the long-term functional outcomes of pediatric patients who undergo AVM surgery and to identify predictors of sustained neurological deficits.

METHODS The authors analyzed a 21-year retrospective cohort of pediatric patients with intracranial AVMs treated with microsurgery at two institutions. The primary outcome was a persistent neurological deficit at last follow-up. Secondary outcome measures included modified Rankin Scale (mRS) score and independent living.

RESULTS Overall, 97 patients (mean age $11.1 \pm 4.5$ years; $56 \%$ female) were treated surgically for intracranial AVMs (mean follow-up 77.5 months). Sixty-four patients (66\%) presented with hemorrhage, and 45 patients (46\%) had neurological deficits at presentation. Radiologically, $39 \%$ of lesions were Spetzler-Martin grade II. Thirty-seven patients (38\%) with persistent neurological deficits at last follow-up were compared with those without deficits; there were no differences in patient age, presenting Glasgow Coma Scale score, AVM size, surgical blood loss, or duration of follow-up. Multivariate analysis demonstrated that a focal neurological deficit on presentation, AVM size $>3 \mathrm{~cm}$, and lesions in eloquent cortex were independent predictors of persistent neurological deficits at long-term follow-up. Overall, $92 \%$ of the children had an $\mathrm{mRS}$ score $\leq 2$ on long-term follow-up.

CONCLUSIONS Pediatric patients with AVMs treated with microsurgical resection have good functional and radiological outcomes. There is a high rate $(38 \%)$ of persistent neurological deficits, which were independently predicted by preoperative deficits, $\mathrm{AVMs}>3 \mathrm{~cm}$, and lesions located in eloquent cortex. This information can be useful in counseling families on the likelihood of long-term neurological deficits after cerebral AVM surgery.

https://thejns.org/doi/abs/10.3171/2019.2.PEDS18731

KEYWORDS arteriovenous malformations; deficit; pediatric; Spetzler-Martin grading system; vascular disorders 
$\mathrm{I}$ NTRACRANIAL arteriovenous malformations (AVMs) in children account for up to $55 \%$ of pediatric hemorrhagic strokes. , $5,6,11,13,24^{2}$ Large experiences with modern treatment modalities coupled with long-term follow-up remain limited. The expected long lifespans of children mean that caregivers are especially interested in outcome measures that directly affect quality of life, including the likelihood of persistent focal neurological deficits (FNDs), the probability of clinical improvement (or decline) over time, and quality-of-life outcomes such as ability to achieve independent living and educational status.

Using a large cohort from two institutions, we examined the clinical presentation, radiological features, and treatment of pediatric patients with intracranial AVMs managed by microsurgical resection. We focused on longterm outcomes with the specific goal of identifying clinical and radiological AVM factors that predict persistent FNDs. We hypothesized that certain clinical and radiological factors might predict long-term functional and neurological outcomes.

\section{Methods \\ Study Design}

This study was a retrospective review of prospectively maintained surgical databases at two pediatric hospitals: Boston Children's Hospital (MA) and Primary Children's Hospital (Salt Lake City, UT). Separate IRB approval was obtained from our institutions with a waiver of informed consent. The article was prepared with the STROBE guidelines. ${ }^{20}$

\section{Inclusion/Exclusion Criteria}

We identified consecutive patients $\leq 18$ years of age who were diagnosed with an intracranial AVM and who were treated with resection from May 1996 through February 2017. We reviewed clinical data and radiological records available from the two institutions for each patient. Patients with arteriovenous fistulas, vein of Galen malformations, and spinal vascular lesions were excluded. Patients with $<12$ months of follow-up were excluded from the analysis.

\section{Data Collection}

Clinical variables included age at surgery, presence of associated hereditary syndromes, other existing medical diagnoses, presenting symptoms and Glasgow Coma Scale (GCS) score, modified Rankin Scale (mRS) score, ${ }^{26}$ any FNDs on presentation, headache, seizures, or intracranial hemorrhage.

Radiological data included review for hemorrhage at presentation, hydrocephalus requiring external ventricular drainage, lesion size $>3 \mathrm{~cm}$ in diameter, lesion location, and key angioarchitectural characteristics (location, size, venous drainage, associated nidal aneurysms, and feeding artery aneurysms).

Treatment data included use of preoperative embolization, iatrogenic sequelae, and timing of surgery.

Radiological outcomes included AVM obliteration after surgery and the development of postoperative residual or recurrent lesions. At each center, the follow-up protocol involves obtaining a brain MR image at 6 months, angiogram at 1 year, and yearly brain MR images up to 5 years after surgery.

Clinical outcomes included length of postoperative follow-up, changes in $\mathrm{mRS}$ score, presence of new or persisting neurological deficits, persistence of headaches, interval development of new seizures, or repeat hemorrhage. Highest level of education and status of independent living were also assessed via delayed telephone interview by trained research assistants.

\section{Statistical Analysis}

We compared children with and without persistent FNDs. Data were summarized using means and standard deviations for continuous variables (Mann-Whitney U-test) and counts and frequencies for categorical variables (Fisher exact test). Univariate statistical analysis was performed to identify the unadjusted association of demographic variables, clinical signs, and radiological characteristics with persistent FND.

Multivariate logistic regression analysis was performed by including variables satisfying statistical entry criteria $(\mathrm{p}<0.2)$ on univariate analysis, as well as clinical factors of interest regardless of statistical association in our univariate analysis. Calibration was examined using the Hosmer-Lemeshow goodness-of-fit test. Statistical significance was established using a value of $\mathrm{p}<0.05$. Data were analyzed using SAS software.

\section{Results \\ Clinical Presentation}

During the 21-year study period, 150 pediatric patients were treated surgically for a confirmed diagnosis of cerebral AVM at these 2 children's hospitals. A total of 97 patients (mean age $11.1 \pm 4.5$ years, $56 \%$ female) satisfied the inclusion criteria and had a minimum of 12 months of follow-up $-78 \%$ from one institution and $22 \%$ from another. The median follow-up duration for the entire cohort was 65 months (range 12-292 months). For children without an FND, the median follow-up duration was 64 months (range 12-201 months), and for children with an FND, the median follow-up duration was 70 months (range 12-292 months). Fifty-three patients were excluded because of lack of clinical and radiological follow-up. Six patients $(6.2 \%)$ had a diagnosis of hereditary hemorrhagic telangiectasia, and 9 $(9.3 \%)$ had other known preexisting medical conditions. Sixty-four patients $(66.0 \%)$ presented with hemorrhage, 64 $(66.0 \%)$ with headache, and $15(15.5 \%)$ with seizures. Approximately half of the children $(n=45,46.4 \%)$ had new neurological deficits at presentation, and the mRS score was $>2$ in 34 patients $(35.1 \%$ ) (Table 1$)$. Other clinical presentation data are provided in Tables 1 and 2 .

\section{Radiological Presentation}

The AVM location was most commonly supratentorial $(\mathrm{n}=86,88.7 \%)$ (Table 3). Approximately two-thirds $(\mathrm{n}=$ $64,66.0 \%$ ) of the patients had intracranial hemorrhage on initial scan. Using the Spetzler-Martin grading scale, ${ }^{25} 29$ (29.9\%) of the AVMs were grade I, 36 (37.1\%) were grade II, $20(20.6 \%)$ were grade III, 7 (7.2\%) were grade IV, and 
TABLE 1. Summary of categorical variables using the Fisher exact test

\begin{tabular}{|c|c|c|c|}
\hline Variable & $\begin{array}{l}\text { No Persistent FND } \\
\qquad(n=60)\end{array}$ & $\begin{array}{l}\text { Persistent FND } \\
\quad(n=37)\end{array}$ & p Value \\
\hline \multicolumn{4}{|l|}{ Clinical/presentation characteristics } \\
\hline Female & $36 / 60(60)$ & 18/37 (49) & 0.3 \\
\hline HHT & $5 / 60(8)$ & $1 / 37(2.7)$ & 0.40 \\
\hline Symptomatic (headache, seizure, hemorrhage, etc.) & $51 / 60(80)$ & $34 / 37(92)$ & 0.36 \\
\hline Other medical disease & $6 / 60(10)$ & $3 / 37(8.1)$ & 1.00 \\
\hline mRS score $>2$ on presentation & $17 / 59(29)$ & $17 / 37(46)$ & 0.124 \\
\hline FND on presentation & $19 / 60(32)$ & $26 / 37(70)$ & $<0.001$ \\
\hline Visual field cut & $7 / 60(12)$ & $8 / 37(22)$ & 0.25 \\
\hline Hemiparesis/hemiplegia & $12 / 60(20)$ & $20 / 37(54)$ & $<0.001$ \\
\hline Cranial nerve deficit & $4 / 60(6.6)$ & $5 / 37(14)$ & 0.29 \\
\hline Hemorrhage & $40 / 60(67)$ & $24 / 37(65)$ & 1.00 \\
\hline Headache & $39 / 60(65)$ & $21 / 37(57)$ & 0.52 \\
\hline GCS score $\leq 8$ & $9 / 59(15)$ & 9/37 (24) & 0.29 \\
\hline Seizures & $8 / 60(13)$ & $7 / 37(19)$ & 0.57 \\
\hline Embolization & $18 / 60(30)$ & $17 / 37(46)$ & 0.13 \\
\hline Bleed with embolization & $1 / 60(1.6)$ & $2 / 37(5.4)$ & 0.56 \\
\hline Urgent op (acutely following rupture) & $24 / 60(40)$ & $11 / 37(30)$ & 0.386 \\
\hline \multicolumn{4}{|l|}{ Radiological factors } \\
\hline Ventricular enlargement/hydrocephalus requiring urgent EVD & $9 / 60(15)$ & 10/37 (27) & 0.19 \\
\hline Mass effect & $15 / 59(25)$ & $13 / 36(36)$ & 0.35 \\
\hline Size $>3 \mathrm{~cm}$ in diameter & $10 / 59(17)$ & $14 / 35(40)$ & 0.016 \\
\hline Lobar location & $31 / 59(53)$ & $23 / 35(66)$ & 0.28 \\
\hline Cerebellar & $10 / 60(17)$ & $2 / 37(5.4)$ & 0.12 \\
\hline Eloquent cortex & $19 / 60(32)$ & $25 / 37(68)$ & $<0.001$ \\
\hline Deep drainage & $17 / 60(28)$ & $16 / 36(44)$ & 0.12 \\
\hline Nidal aneurysm & $3 / 60(5)$ & $4 / 37(11)$ & 0.42 \\
\hline Angiographically confirmed obliteration & $50 / 60(83)$ & 29/37 (78) & 0.59 \\
\hline Interval recurrence & $9 / 59(15)$ & 7/37 (19) & 0.78 \\
\hline \multicolumn{4}{|l|}{ Long-term clinical outcomes } \\
\hline Survival at $5 \mathrm{yrs}^{*}$ & $35 / 36(97)$ & $23 / 23(100)$ & 1.00 \\
\hline Living independently (ADLs) & $55 / 59(93)$ & 28/37 (76) & 0.028 \\
\hline Visual field cut & $2 / 59(3.3)$ & 15/37 (41) & $<0.001$ \\
\hline Hemiparesis/hemiplegia & $1 / 59(1.6)$ & $21 / 37(57)$ & $<0.001$ \\
\hline Cranial nerve deficit & $0 / 59(0)$ & 7/37 (19) & 0.001 \\
\hline Headaches & $8 / 59(14)$ & $6 / 37(16)$ & 0.771 \\
\hline New seizures & $9 / 59(15)$ & $8 / 37$ (22) & 0.427 \\
\hline Rebleed & $1 / 60(1.6)$ & $0 / 37(0)$ & 1.00 \\
\hline
\end{tabular}

$A D L=$ activities of daily living; $E V D$ = external ventricular drainage; $H H T$ = hereditary hemorrhagic telangiectasia .

Boldface type indicates statistical significance.

* Of patients with $\geq 5$ years of follow-up (total $n=59$ ).

$1(1.0 \%)$ was grade $\mathrm{V}$, with significant differences in the distribution of grades between the two cohorts $(p=0.012)$ (Table 4). Most AVMs (75.3\%) were small $(\leq 3 \mathrm{~cm})$, with a mean size of $2.4 \pm 1.22 \mathrm{~cm}$ (in greatest axis). Thirty-three (34.0\%) AVMs had deep venous drainage, and 7 (7.2\%) patients had an associated aneurysm on an associated feeding artery or at an intranidal location; 44 (45.4\%) lesions were located in eloquent cortex (Table 1).

\section{Treatment Data}

All patients underwent AVM resection, with 35 (36.1\%) requiring an emergent operation (including clot evacuation for increased intracranial pressure) at presentation. Nineteen patients (19.6\%) required placement of an external ventricular drain for hydrocephalus. Thirty-five patients (36.1\%) underwent preoperative embolization. The mean estimated blood loss for surgery was $252 \mathrm{ml}$. Complica- 
TABLE 2. Summary of continuous variables using the Mann-Whitney U-test

\begin{tabular}{|c|c|c|c|c|c|c|c|}
\hline \multirow[b]{2}{*}{ Variable } & \multicolumn{3}{|c|}{ No Persistent FND } & \multicolumn{3}{|c|}{ With Persistent FND } & \multirow[b]{2}{*}{$\mathrm{p}$ Value } \\
\hline & No. & Mean \pm SD & 25/50/75th Percentile & No. & Mean \pm SD & 25/50/75th Percentile & \\
\hline Age at op (mean in yrs) & 60 & $11.1 \pm 4.35$ & $8.23 / 11.5 / 14.5$ & 37 & $11.4 \pm 4.53$ & $9.08 / 11 / 13.9$ & 0.77 \\
\hline Presenting GCS score & 59 & $13.1 \pm 3.6$ & $14 / 15 / 15$ & 37 & $12.1 \pm 4.2$ & $8.5 / 15 / 15$ & 0.16 \\
\hline Lesion size $(\mathrm{cm})$ & 57 & $2.3 \pm 1.08$ & $1.6 / 2 / 2.55$ & 33 & $2.81 \pm 1.5$ & $1.85 / 2.5 / 3.45$ & 0.16 \\
\hline Time to FU (mos) & 60 & $76.5 \pm 51.6$ & $30.5 / 64 / 112$ & 37 & $80.3 \pm 63$ & $36.5 / 70 / 101$ & 0.98 \\
\hline Estimated blood loss (ml) & 50 & $265 \pm 304$ & $100 / 150 / 363$ & 34 & $242 \pm 256$ & $100 / 150 / 263$ & 0.88 \\
\hline Mos until FU imaging & 59 & $51.8 \pm 45.9$ & $16 / 34 / 77$ & 37 & $56.7 \pm 44.4$ & $25.5 / 48 / 72.5$ & 0.31 \\
\hline
\end{tabular}

tions occurred in $3(8.6 \%)$ of 35 embolization procedures (all hemorrhages). There were no intraoperative deaths.

\section{Radiological and Clinical Outcome Data}

Seventy-nine patients (81.4\%) had angiographically confirmed obliteration of the AVM after surgery (within the operative hospitalization). There was an association between having recurrent/residual lesions identified on delayed angiography and not having undergone postoperative angiography during the intraoperative or immediate postoperative period $(\mathrm{p}<0.001)$. Sixteen patients had an interval recurrence (Table 1), only 4 of whom had confirmed obliteration on immediate postoperative angiography. Twelve $(75 \%)$ of the 16 patients who had recurrent lesions initially presented with acute AVM hemorrhage. Nine of 16 patients were taken for urgent surgery $(<24$ hours). One patient experienced a repeat hemorrhage from a recurrent AVM 15 years after resection.

Clinically, of the 97 patients with long-term follow-up (mean 77.5 months), 37 (38.1\%) had a persistent FND at last follow-up. Five patients (17.2\%) with Spetzler-Martin grade I lesions, 13 (36.1\%) with grade II lesions, 10 (50\%) with grade III, 5 (71.4\%) with grade IV lesions, and the only patient (100\%) with a Spetzler-Martin grade V lesion had a persistent FND on follow-up. Specific deficits are quantified in Table 1.

Fifteen patients had visual field deficits preoperatively, and 17 had visual deficits postoperatively. There were 8 persistent visual field deficits (6 occipital, 1 temporal, and 1 parietal), 7 resolved visual field cuts, and 9 new visual field cuts ( 4 occipital, 4 temporal, and 1 thalamic). Hemiparesis/hemiplegia persisted in 16 patients and resolved on long-term follow-up in 16 patients. Six patients developed new hemiparesis/hemiplegia (2 parietal and 1 each

TABLE 3. Location of AVMs in 97 patients

\begin{tabular}{lc}
\hline \multicolumn{1}{c}{ Location } & No. of Patients \\
\hline Temporal & 18 \\
\hline Frontal & 22 \\
\hline Parietal & 18 \\
\hline Occipital & 19 \\
\hline Cerebellar & 12 \\
\hline Other (thalamic, brainstem) & 8 \\
\hline
\end{tabular}

occipital, temporal, cerebellar, and thalamic). There were 9 cranial nerve deficits preoperatively: 7 resolved and 2 persisted. There were 5 new cranial nerve deficits postoperatively that persisted until last follow-up (Table 5).

Overall, $58(98.3 \%)$ of 59 patients were alive at $\geq 5$-year follow-up, with 1 death from a residual AVM hemorrhage. Eighty-three patients $(85.5 \%)$ were living independently at last follow-up. Forty-one patients (mean age at surgery $12 \pm 4$ years; mean follow-up duration $75.8 \pm 51$ months) were available to complete telephone interviews regarding education status (Table 6): $7.3 \%$ completed or were enrolled currently in grade school, $51.2 \%$ completed high school, $29.2 \%$ completed college, $7.3 \%$ completed professional school, and $4.9 \%$ were not in school because of poor grades. Overall, $92 \%$ of children did well, with an $\mathrm{mRS}$ score $\leq 2$ on long-term follow-up. The delta $\mathrm{mRS}$ score (change from initial presentation to last follow-up) was calculated for each available patient (Fig. 1). Approximately $47 \%$ of the children had an improvement in their mRS score over time, $36 \%$ had a stable mRS score, and only $11 \%$ had a worsened mRS score. Eighty-six (86.5\%) of 93 patients (no deficit [93\%] vs deficit [76\%], $\mathrm{p}=0.03$ ) were living independently at their last follow-up.

\section{Identifying Risk Factors Predictive of Sustained Deficits}

When comparing patients with and without persistent FNDs at last follow-up, there was no difference in mean age, presenting GCS score, AVM size, operative blood loss, or length of follow-up between the two cohorts (Table 1). Univariate analysis demonstrated that FNDs on presentation ( $32 \%$ vs $70 \%, \mathrm{p}<0.001)$, specifically hemiparesis or hemiplegia ( $20 \%$ vs $54 \%, \mathrm{p}<0.001)$, size $>3 \mathrm{~cm}$ in diam-

TABLE 4. Spetzler-Martin graded of 93 surgically treated AVMs with data available

\begin{tabular}{ccc}
\hline Spetzler-Martin Grade & $\begin{array}{c}\text { No Persistent FND } \\
(\mathrm{n}=59)\end{array}$ & $\begin{array}{c}\text { Persistent FND } \\
(\mathrm{n}=34)\end{array}$ \\
\hline I & $24(41 \%)$ & $5(15 \%)$ \\
\hline II & $23(39 \%)$ & $13(38 \%)$ \\
\hline III & $10(17 \%)$ & $10(29 \%)$ \\
\hline IV & $2(3.4 \%)$ & $5(15 \%)$ \\
\hline V & $0(0 \%)$ & $1(2.9 \%)$ \\
\hline
\end{tabular}

Values are presented as the number (\%) of AVMs. 
TABLE 5. Type of neurological deficits on initial presentation and postoperatively in 97 patients

\begin{tabular}{lcc}
\hline \multicolumn{1}{c}{ Deficit } & Initial Presentation & Postoperatively \\
\hline FND & $45(46 \%)$ & $37(38 \%)$ \\
\hline Visual field deficit & $15(15 \%)$ & $17(18 \%)$ \\
\hline Hemiparesis/hemiplegia & $32(33 \%)$ & $22(23 \%)$ \\
\hline Cranial nerve deficit & $9(9 \%)$ & $7(7 \%)$ \\
\hline
\end{tabular}

Values are presented as the number (\%) of patients. Some patients had more than one deficit so numbers do not total $100 \%$.

eter $(17 \%$ vs $38 \%, \mathrm{p}=0.016)$, and lesions in eloquent cortex $(32 \%$ vs $68 \%, \mathrm{p}<0.001)$ had an unadjusted association with persistent FNDs on long-term follow-up (Table 2).

The multivariate regression analysis demonstrated that an FND on presentation (adjusted OR [aOR] 7.43 [95\% CI 2.00-27.5]), AVM size $>3 \mathrm{~cm}$ in diameter (aOR 2.97 [95\% CI 0.93-9.586], and lesions in eloquent cortex (aOR 2.67 [95\% CI 0.964-7.44]) were independent predictors of persistent FND at long-term follow-up (Table 7). The Hosmer-Lemeshow statistic was not significant, consistent with adequate model calibration.

\section{Discussion}

We present a large cohort of intracranial AVMs surgically treated at two centers in children with long-term follow-up. Previous reports of treatment outcomes have been limited by smaller cohort size., , $, 5,10,11,15,19,22$ Our data clarify the clinical and radiological presentation of this population and provide perioperative and long-term outcomes. We identified 3 independent risk factors for persistent FND in children who undergo surgical treatment for cerebral AVMs. An FND on presentation, AVM size $>3$ $\mathrm{cm}$, and cerebral AVMs located in eloquent cortex were independently associated with persistent FNDs on longterm follow-up. These data will help to inform the treatment of children with AVMs when considering resection.

Importantly, this study differentiates itself from others by providing a novel approach for examining and predicting long-term functional outcomes for children and by providing potential information when counseling children and families on long-term neurological deficits in the setting of cerebral AVM surgery.

\section{Novelty of the Study and Follow-Up}

In addition to increasing the overall quantity of data (in terms of both patient number and follow-up length), our results reveal 4 important findings relevant to the outcomes after surgical management of pediatric AVMs.

First, our study improves our understanding of the evolving role of perioperative embolization as an adjunct in treating cerebral AVMs before surgery. Although there was an $8.5 \%$ rate of hemorrhagic complications during embolization, they did not correlate with focal deficits on follow-up, indicating that embolization is a safe treatment adjunct in the long term. Second, this multicenter cohort highlights the overall good long-term outcomes of these patients, with stable or improving mRS scores over time,
TABLE 6. Education level attained by children after surgical treatment for AVM ( $n=41$ respondents)

\begin{tabular}{lcc}
\hline \multicolumn{1}{c}{ Level of Education* } & Frequency & $\begin{array}{c}\text { \% of Those } \\
\text { Responding }\end{array}$ \\
\hline Grade school & 3 & 7.3 \\
\hline High school & 21 & 51.2 \\
\hline College & 12 & 29.2 \\
\hline Professional school & 3 & 7.3 \\
\hline Not in school due to poor grades & 2 & 4.9 \\
\hline * Varying ages of respondents. & &
\end{tabular}

high rates of independent living, and advanced educational success. Third, this work reinforces the importance of high-quality intra- or perioperative angiography to confirm AVM obliteration. In 16 patients with recurrence, only 4 had confirmed obliteration on immediate postoperative angiography; the rest did not undergo angiography. Thus, the recurrences may have resulted from failure to recognize incomplete resection or residual lesion. Fourth, our results offer insights into the risks of emergent operation. Twelve (75\%) of 16 recurrences initially presented with acute hemorrhage, and 9 had urgent surgery ( $<24$ hours); thus, there is a possibility that acute hemorrhage or cerebral edema skewed the recognition of the entire vascular lesion, thus contributing to the interval recurrence rate.

Equally important to understanding the patterns and risks for persistent FNDs is the need for dedicated longterm clinical and radiological follow-up for these children. There is a risk of recurrence, clinical deterioration, and rehemorrhage. In treating pediatric AVMs, counseling patients and families about treatment options, procedural morbidity, and obliteration rates is critical. ${ }^{9}$ Our data help to clarify factors that influence the risk of long-term neurological disability, affording physicians specific toolsperioperative angiography, for example - and identifiable risk factors (such as emergent operation vs elective resection) that can now guide treatment and follow-up with greater accuracy.

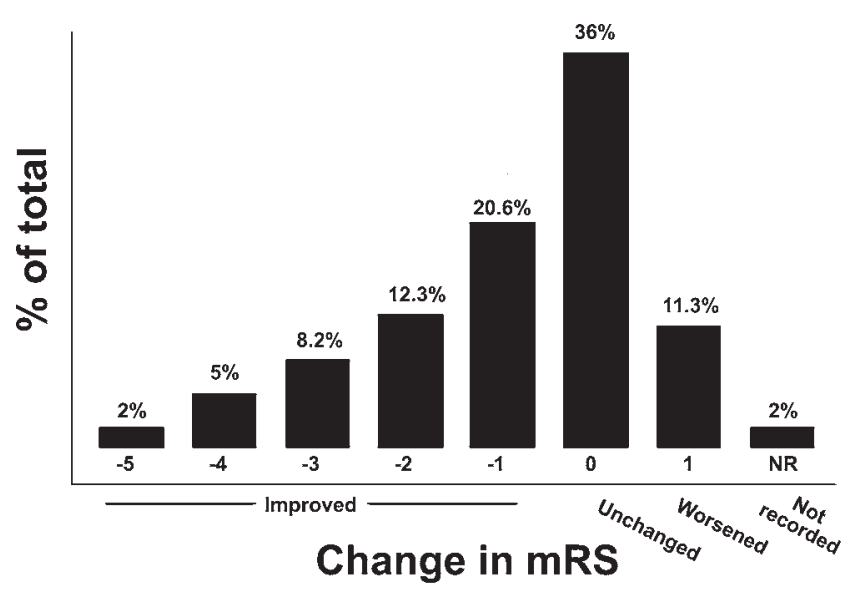

FIG. 1. Bar graph demonstrating the change in $\mathrm{mRS}$ scores from initial presentation to last follow-up. 
TABLE 7. Multivariate analysis for independent risk factors associated with persistent neurological deficits after AVM resection

\begin{tabular}{lccl}
\hline \multicolumn{1}{c}{ Variable } & aOR & $95 \% \mathrm{Cl}$ & $\mathrm{p}$ Value \\
\hline FND on presentation & 7.43 & $\mathbf{2 . 0 0 - 2 7 . 5}$ & $\mathbf{0 . 0 0 3}$ \\
\hline Size $>3 \mathrm{~cm}$ in diameter & $\mathbf{2 . 9 7}$ & $\mathbf{0 . 9 3 - 9 . 5 8 6}$ & $\mathbf{0 . 0 6}$ \\
\hline Eloquent cortex & $\mathbf{2 . 6 7}$ & $\mathbf{0 . 9 6 4 - 7 . 4 4}$ & $\mathbf{0 . 0 5}$ \\
\hline mRS score $>2$ on presentation & 0.311 & $0.311-3.69$ & 0.91 \\
\hline Hemorrhage on presentation & 0.57 & $0.13-2.50$ & 0.45 \\
\hline Seizure on presentation & 1.58 & $0.38-6.53$ & 0.53 \\
\hline
\end{tabular}

Boldface type indicates statistically significant values $(p<0.05)$.

\section{ARUBA Study and Rebleeding Rates}

Our investigation has additional utility when viewed within the context of the recent ARUBA (A Randomized Trial of Unruptured Brain AVMs) study. ${ }^{18}$ Our current study challenges the ARUBA data-at least for childrenby demonstrating the predictors of neurological morbidity and showing that children do well across several outcome metrics (mRS score, independence, and education) after microsurgical treatment. The additional lifelong cumulative risk of rupture and the potential for morbidity from AVM hemorrhage are important factors that justify treatment in appropriately selected patients. The Scottish Audit of Intracranial Vascular Malformations supported the findings of the ARUBA study but also judged that cumulative rates of death or handicap with follow-up $>12$ years may favor treatment. ${ }^{1}$ Whereas the ARUBA and Scottish Audit of Intracranial Vascular Malformations studies were focused on adult unruptured AVMs, the natural history and longevity in children demonstrate a need for different treatment thresholds in pediatric patients.

Interestingly, hemorrhage was not significantly associated with the primary outcome. Although some previous reports have demonstrated lower neurological complication rates, ${ }^{7,17}$ the overall neurological and long-term clinical outcomes in this cohort study are quite good. No comparative data exist for larger series of patients treated with embolization only or radiosurgery. Delayed cognitive sequelae of radiation therapy are of interest, especially in the pediatric population. ${ }^{8,12,21,23}$ Our data also support the routine use of immediate postoperative angiography to ensure AVM obliteration, given the association with residual lesions and not obtaining an angiogram in the immediate postoperative period $(\mathrm{p}<0.001)$. Although Blauwblomme et al. ${ }^{3}$ demonstrated that associated aneurysms and deep venous drainage as AVM characteristics were independent risk factors for rebleeding in pediatric AVMs, we did not find these factors to be associated with persistent deficit.

\section{Long-Term Functional Outcomes}

Long-term functional outcomes are of particular interest when treating pediatric patients. We attempted to augment standardized outcome metrics (such as the mRS score) with more intuitive data that can help inform patients and families with a more complete picture when predicting outcomes. An overwhelmingly majority of patients
(92\%) had an mRS score of 0-2 on long-term follow-up, indicating a durable result. Worsening mRS score, which was seen in a small subset of patients in this series, may occur in the setting of recurrent seizure activity secondary to AVM rupture, hemosiderin, persistent headaches, or cognitive dysfunction, which could be a result of AVM rupture at an early age with long-term sequelae.

More relatable data included overall survival, independent living, and education status. For patients with $\geq$ 5 years of follow-up, only one death $(1.7 \%)$ occurred, related to a residual AVM. Overall, $86 \%$ (83 of 97) of the patients were living independently at long-term follow-up. When discussing outcomes, the long-term educational potential for children who have undergone craniotomy for pediatric AVMs is of significant interest. Overall, 29\% of respondents completed a college-level education, with $7.3 \%$ achieving professional school completion. We believe outcome measures such as educational achievement, neuropsychological testing, and intelligence testing should be more commonplace in pediatric studies because of the longevity and growth occurring in this population.

\section{Recurrent AVMs in Pediatric Patients}

In this series, 16 patients had an interval recurrence identified on follow-up imaging. Not having an immediate angiogram, acute hemorrhage, and the need for urgent surgery likely contributed to the recurrence rate in this series. In fact, 12 of 16 patients with recurrent lesions did not undergo immediate postoperative angiography; thus, these recurrences may in fact represent residual lesions rather than recurrent ones. The rates of recurrence tend to be higher in children (13\%-14\%) than in adults even after complete obliteration, ${ }^{15,16}$ because AVM formation is an "active process" and immature blood vessels in the resection cavity may predispose children to recurrent AVM formation. ${ }^{14}$ Thus, close short- and long-term radiological surveillance is necessary for children with AVMs, despite a "clean" immediate postoperative angiogram, even though a number of patients did not have an immediate completion angiogram. Each center currently follows a protocol that calls for surveillance for 5 years; given that one patient in this investigation experienced a recurrence at $>5$ years, yearly surveillance for a longer period may be necessary.

\section{Cause of Neurological Deficits}

Overall, 45 patients (46\%) presented with an FND (Table 7). We surmise that a majority of the neurological deficits come from the initial ictus of hemorrhage and are spontaneous in origin. The information in Table 7 helps in the understanding of neurological deficits and their propensity to improve over time. It is difficult to make assumptions about the prevalence and persistence of visual field cuts as some may have resolved and been a result of surgical approach and resection (majority occipital lobe lesions; 75\%). Thus, the results of persistent long-term deficits should be taken in this light. Despite the presence of these deficits, however, the mRS score and independence with respect to activities of daily living seem to be unaffected, allowing a potentially excellent quality of life. 


\section{Limitations}

We conducted a retrospective multicenter study with inherent recall bias. The most notable limitation is the elimination of 53 patients based on limited follow-up information. Although both centers have recommended follow-up paradigms, the tertiary nature of each of the centers drawing patients from long distances means that follow-up information can be difficult to obtain in a reliable fashion. We chose to include patients with only 12 months of follow-up as the most responsible manner to undertake the study given the hypothesis and objectives. Current treatment of AVMs includes surgery, stereotactic radiosurgery, endovascular embolization, or a combination of these. In this study, we only included patients treated initially with surgery with/without embolization as an adjunct. Information collected as a proxy for cognitive outcome included a telephone questionnaire for a fraction of the study cohort and thus is subject to bias. In addition, the varying ages of respondents and ages of initial surgical intervention make direct comparison of these metrics difficult.

There are inherent shortcomings when assessing independent functionality in children, specifically with regard to the mRS score. Although educational level can be used as a measure for cognitive function, the variability in follow-up and age ranges among the respondents limit the conclusions drawn from the data presented. Despite these limitations, we believe this study provides valuable information on the long-term clinical outcomes and predicting persistent FNDs in children undergoing surgery for cerebral AVMs and can be useful in counseling of children and families on the long-term neurological deficits in the setting of cerebral AVM surgery.

\section{Conclusions}

Pediatric AVMs treated with microsurgical resection have good functional and radiological outcomes, particularly when perioperative angiograms are used to confirm obliteration. We identified 3 presentation characteristics that were independently associated with persistent FNDs on long-term assessment after surgical treatment for cerebral AVMs in children: FND on initial presentation, AVM size $>3 \mathrm{~cm}$, and AVM location in the eloquent cortex. This information can be useful in counseling of children and families on potential long-term neurological deficit in the setting of cerebral AVM surgery. Future study comparing long-term outcomes, both cognitive and neurological, across treatment modalities is needed.

\section{Acknowledgments}

This research was supported by the AANS/CNS Traveling Fellowship Award given to Vijay M. Ravindra, MD, MSPH.

\section{References}

1. Al-Shahi Salman R, White PM, Counsell CE, du Plessis J, van Beijnum J, Josephson CB, et al: Outcome after conservative management or intervention for unruptured brain arteriovenous malformations. JAMA 311:1661-1669, 2014

2. Beslow LA, Licht DJ, Smith SE, Storm PB, Heuer GG, Zimmerman RA, et al: Predictors of outcome in childhood intracerebral hemorrhage: a prospective consecutive cohort study. Stroke 41:313-318, 2010
3. Blauwblomme T, Bourgeois M, Meyer P, Puget S, Di Rocco F, Boddaert N, et al: Long-term outcome of 106 consecutive pediatric ruptured brain arteriovenous malformations after combined treatment. Stroke 45:1664-1671, 2014

4. Bristol RE, Albuquerque FC, Spetzler RF, Rekate HL, McDougall CG, Zabramski JM: Surgical management of arteriovenous malformations in children. J Neurosurg 105 (2 Suppl):88-93, 2006

5. Darsaut TE, Guzman R, Marcellus ML, Edwards MS, Tian L, Do HM, et al: Management of pediatric intracranial arteriovenous malformations: experience with multimodality therapy. Neurosurgery 69:540-556, 2011

6. Ellis MJ, Armstrong D, Vachhrajani S, Kulkarni AV, Dirks PB, Drake JM, et al: Angioarchitectural features associated with hemorrhagic presentation in pediatric cerebral arteriovenous malformations. J Neurointerv Surg 5:191-195, 2013

7. Gross BA, Duckworth EA, Getch CC, Bendok BR, Batjer $\mathrm{HH}$ : Challenging traditional beliefs: microsurgery for arteriovenous malformations of the basal ganglia and thalamus. Neurosurgery 63:393-411, 2008

8. Gross BA, Ropper AE, Du R: Vascular complications of stereotactic radiosurgery for arteriovenous malformations. Clin Neurol Neurosurg 115:713-717, 2013

9. Gross BA, Storey A, Orbach DB, Scott RM, Smith ER: Microsurgical treatment of arteriovenous malformations in pediatric patients: the Boston Children's Hospital experience. J Neurosurg Pediatr 15:71-77, 2015

10. Hladky JP, Lejeune JP, Blond S, Pruvo JP, Dhellemmes P: Cerebral arteriovenous malformations in children: report on 62 cases. Childs Nerv Syst 10:328-333, 1994

11. Humphreys RP, Hoffman HJ, Drake JM, Rutka JT: Choices in the 1990s for the management of pediatric cerebral arteriovenous malformations. Pediatr Neurosurg 25:277-285, 1996

12. Izawa M, Chernov M, Hayashi M, Nakaya K, Kamikawa S, Kato K, et al: Management and prognosis of cysts developed on long-term follow-up after Gamma Knife radiosurgery for intracranial arteriovenous malformations. Surg Neurol 68:400-406, 2007

13. Jordan LC, Johnston SC, Wu YW, Sidney S, Fullerton HJ: The importance of cerebral aneurysms in childhood hemorrhagic stroke: a population-based study. Stroke 40:400-405, 2009

14. Kader A, Goodrich JT, Sonstein WJ, Stein BM, Carmel PW, Michelsen WJ: Recurrent cerebral arteriovenous malformations after negative postoperative angiograms. J Neurosurg 85:14-18, 1996

15. Klimo P Jr, Rao G, Brockmeyer D: Pediatric arteriovenous malformations: a 15-year experience with an emphasis on residual and recurrent lesions. Childs Nerv Syst 23:31-37, 2007

16. Lang SS, Beslow LA, Bailey RL, Vossough A, Ekstrom J, Heuer GG, et al: Follow-up imaging to detect recurrence of surgically treated pediatric arteriovenous malformations. J Neurosurg Pediatr 9:497-504, 2012

17. Lawton MT, Kim H, McCulloch CE, Mikhak B, Young WL: A supplementary grading scale for selecting patients with brain arteriovenous malformations for surgery. Neurosurgery 66:702-713, 2010

18. Mohr JP, Parides MK, Stapf C, Moquete E, Moy CS, Overbey JR, et al: Medical management with or without interventional therapy for unruptured brain arteriovenous malformations (ARUBA): a multicentre, non-blinded, randomised trial. Lancet 383:614-621, 2014

19. Nair AP, Kumar R, Mehrotra A, Srivastava AK, Sahu RN, Nair P: Clinical, radiological profile and outcome in pediatric Spetzler-Martin grades I-III arteriovenous malformations. Childs Nerv Syst 28:593-598, 2012

20. Noah N: The STROBE initiative: STrengthening the Report- 
ing of OBservational studies in Epidemiology (STROBE). Epidemiol Infect 136:865, 2008

21. Pan HC, Sheehan J, Stroila M, Steiner M, Steiner L: Late cyst formation following gamma knife surgery of arteriovenous malformations. J Neurosurg 102 Suppl:124-127, 2005

22. Sanchez-Mejia RO, Chennupati SK, Gupta N, Fullerton H, Young WL, Lawton MT: Superior outcomes in children compared with adults after microsurgical resection of brain arteriovenous malformations. J Neurosurg 105 (2 Suppl):82-87, 2006

23. Shin M, Kawahara N, Maruyama K, Tago M, Ueki K, Kirino T: Risk of hemorrhage from an arteriovenous malformation confirmed to have been obliterated on angiography after stereotactic radiosurgery. J Neurosurg 102:842-846, 2005

24. Smith ER, Butler WE, Ogilvy CS: Surgical approaches to vascular anomalies of the child's brain. Curr Opin Neurol 15:165-171, 2002

25. Spetzler RF, Martin NA: A proposed grading system for arteriovenous malformations. J Neurosurg 65:476-483, 1986

26. van Swieten JC, Koudstaal PJ, Visser MC, Schouten HJ, van Gijn J: Interobserver agreement for the assessment of handicap in stroke patients. Stroke 19:604-607, 1988

\section{Disclosures}

The authors report no conflict of interest concerning the materials or methods used in this study or the findings specified in this paper.

\section{Author Contributions}

Conception and design: Ravindra, Smith. Acquisition of data: Ravindra, Eli, Lanpher, Klein. Analysis and interpretation of data: Ravindra, Eli, Lanpher, Klein. Drafting the article: Ravindra. Critically revising the article: Ravindra, Bollo, Griauzde, Brockmeyer, Kestle, Couldwell, Scott, Smith. Reviewed submitted version of manuscript: Ravindra, Bollo, Eli, Griauzde, Klein, Zhu, Brockmeyer, Kestle, Couldwell, Scott, Smith. Approved the final version of the manuscript on behalf of all authors: Ravindra. Statistical analysis: Ravindra, Zhu. Administrative/technical/material support: Lanpher.

\section{Supplemental Information \\ Previous Presentations}

Portions of this work were presented as an oral abstract at the American Association of Neurological Surgeons/Congress of Neurological Surgeons Section on Pediatric Neurological Surgery Meeting, Houston, Texas, November 28, 2017, to December 1, 2017.

\section{Current Affiliations}

Dr. Ravindra: Department of Surgery, Texas Children's Hospital, Houston, TX.

\section{Correspondence}

Vijay M. Ravindra: University of Utah, Salt Lake City, UT. neuropub@hsc.utah.edu. 